\title{
Characterizing niche differentiation among marine consumers with amino acid $\delta^{13} \mathrm{C}$ fingerprinting
}

\author{
Thomas Larsen ${ }^{1}$, Thomas Hansen ${ }^{2}$, and Jan Dierking ${ }^{2}$ \\ ${ }^{1}$ Max Planck Institute for the Science of Human History \\ ${ }^{2}$ GEOMAR Helmholtz Centre for Ocean Research Kiel
}

May 5, 2020

\begin{abstract}
Marine food webs are highly compartmentalized and characterizing the trophic niches among consumers is important for predicting how impact from human activities affect the structuring and functioning of marine food webs. Biomarkers such as bulk stable isotopes have proven to be powerful tools to elucidate trophic niches, but they may lack in resolution, particularly when spatio-temporal variability in a system is high. To close this gap, we investigated whether carbon isotope $\left(\delta^{13} \mathrm{C}\right)$ patterns of essential amino acids (EAAs), also termed $\delta^{13}$ AA fingerprints, can characterize niche differentiation in a highly dynamic marine system. We tested the ability of $\delta^{13}$ AA fingerprints to differentiate trophic niches among six functional groups and ten individual species in the Baltic Sea. We also tested whether fingerprints of the common zooplanktivorous fishes, herring and sprat, differ among four Baltic Sea regions with different biochemical conditions and phytoplankton assemblages. Additionally, we investigated how these results compared to bulk $\mathrm{C}$ and $\mathrm{N}$ isotope data for the same sample set. We found significantly different $\delta^{13}$ AA fingerprints among all six functional groups. Species differentiation was in comparison less distinct, due to partial convergence of the species' fingerprints within functional groups. Herring and sprat displayed region specific $\delta^{13}$ AA fingerprints indicating that this approach could be used as a migratory marker. Bulk isotope data had a lower power to differentiate between trophic niches, but may provide more easily interpretable information about relative trophic position than the fingerprints. We conclude that $\delta^{13} \mathrm{AA}$ fingerprinting has a strong potential to advance our understanding of ecological niches, and trophic linkages from producers to higher trophic levels in dynamic marine systems. Given how management practices of marine resources and habitats are reshaping the structure and function of marine food webs, implementing new and powerful tracer methods are urgently needed to improve the knowledge base for policy makers.
\end{abstract}

Characterizing niche differentiation among marine consumers with amino acid $\delta^{13} \mathrm{C}$ fingerprinting Thomas Larsen ${ }^{1+}$, Thomas Hansen ${ }^{2}$, Jan Dierking ${ }^{2}$

${ }^{1}$ Max Planck Institute for the Science of Human History, Kahlaische Strasse 10, 07745 Jena, Germany

${ }^{2}$ GEOMAR Helmholtz Centre for Ocean Research Kiel, Düsternbrooker Weg 20, 24105 Kiel, Germany

+Email: larsen@shh.mpg.de

Key words: Baltic Sea, carbon stable isotopes, diet partitioning, fish diets, food web reconstruction, migration tracking, phytoplankton, predator-prey dynamics

Abstract

Marine food webs are highly compartmentalized and characterizing the trophic niches among consumers is important for predicting how impact from human activities affect the structuring and functioning of marine food webs. Biomarkers such as bulk stable isotopes have proven to be powerful tools to elucidate trophic niches, but they may lack in resolution, particularly when spatio-temporal variability in a system is high. To 
close this gap, we investigated whether carbon isotope $\left(\delta^{13} \mathrm{C}\right)$ patterns of essential amino acids (EAAs), also termed $\delta^{13} \mathrm{C}_{\mathrm{AA}}$ fingerprints, can characterize niche differentiation in a highly dynamic marine system. We tested the ability of $\delta^{13} \mathrm{C}_{\mathrm{AA}}$ fingerprints to differentiate trophic niches among six functional groups and ten individual species in the Baltic Sea. We also tested whether fingerprints of the common zooplanktivorous fishes, herring and sprat, differ among four Baltic Sea regions with different biochemical conditions and phytoplankton assemblages. Additionally, we investigated how these results compared to bulk $\mathrm{C}$ and $\mathrm{N}$ isotope data for the same sample set. We found significantly different $\delta^{13} \mathrm{C}_{\mathrm{AA}}$ fingerprints among all six functional groups. Species differentiation was in comparison less distinct, due to partial convergence of the species' fingerprints within functional groups. Herring and sprat displayed region specific $\delta^{13} \mathrm{C}_{\mathrm{AA}}$ fingerprints indicating that this approach could be used as a migratory marker. Bulk isotope data had a lower power to differentiate between trophic niches, but may provide more easily interpretable information about relative trophic position than the fingerprints. We conclude that $\delta^{13} \mathrm{C}_{\mathrm{AA}}$ fingerprinting has a strong potential to advance our understanding of ecological niches, and trophic linkages from producers to higher trophic levels in dynamic marine systems. Given how management practices of marine resources and habitats are reshaping the structure and function of marine food webs, implementing new and powerful tracer methods are urgently needed to improve the knowledge base for policy makers.

\section{INTRODUCTION}

Direct pressures on marine systems such as increasing temperatures, eutrophication, introduction of nonindigenous species and overfishing are affecting the performance of individual species and the structure of entire systems. Examples of these consequences include the malnutrition of ecologically and commercially important fish species (Eero et al. 2015), niche shifts following the introduction of non-indigenous species (Ojaveer et al. 2017), and evidence for system wide shifts in many regions (Alheit et al. 2005). In this context, identifying organic matter sources at the base of the food web is key for understanding resource partitioning and trophic niche differentiation across time and space.

How marine communities differentiate and partition resources among species are often poorly understood due to the complexity of marine food webs and methodological constraints. Diet identification has traditionally relied on visual taxonomic assessment of stomach and faecal contents (Hyslop 1980), but visual assessments are now increasingly complemented with DNA metabarcoding (Bowser, Diamond \& Addison 2013). While the taxonomic resolution of these methods can be high, they only provide instant snapshots of ingested diets provided that the identifiable fragments or DNA sequences are intact. Obtaining intact sequences can be logistically challenging when assessing multiple species over space and time. In comparison, it is possible to integrate dietary histories with stable isotope ratios, since the diet derived building blocks for animal tissues are sourced over time. Stable isotopes of elements can be informative of diet sources because lighter stable isotopes enter reactions and physical processes at faster rates than heavier stable isotopes, resulting in different isotope ratios among different organic pools. The rate by which elements shifts their isotopic ratios during trophic transfer differ greatly: elements such as carbon and sulfur are used as source tracers because they hardly discriminate (Mittermayr et al 2014) in contrast to nitrogen that is used as a marker of trophic position (Vander Zanden and Rasmussen 1999). However, isotope ratios of whole ("bulk") tissues often lack source specificity because of variable, and at times, unpredictable isotope discriminate processes and isotope baseline values for different systems (Post 2002; Fry 2006). To overcome these limitations, ecologists are increasingly using compound specific isotope analyses (CSIA), in which stable isotope ratios are determined for individual compounds, as a complementary approach (Whiteman et al. 2019).

CSIA of protein amino acids has emerged as one of the most promising approaches to trace the origins and fate of food sources (McClelland \& Montoya 2002; O'Brien, Fogel \& Boggs 2002). Amino acids (AAs) are among the major conduits of organic carbon in food webs, and well suited as a source tracer because metazoans cannot synthesize the carbon backbones of about half of the 20 protein AAs de novo. Instead, metazoans depend on essential amino acids (EAA) from food sources (McMahon et al.2010) or bacterial symbionts (Larsen et al. 2016b). EAA are powerful source tracers because $\delta^{13} \mathrm{C}_{\mathrm{EAA}}$ values remain largely conserved through trophic transfer and because the producers of these EAA, algae, bacteria, fungi and 
vascular plants each generate unique $\delta^{13} \mathrm{C}_{\mathrm{EAA}}$ patterns or fingerprints (Scott et al. 2006; Larsen et al. 2009; Larsen et al. 2013). See the Textbox for an illustrative explanation of the $\delta^{13} \mathrm{C}_{\mathrm{EAA}}$ fingerprinting technique. Thus, by analysing $\delta^{13} \mathrm{C}_{\mathrm{EAA}}$ ecologists can circumvent the problem of variable and unknown isotopic fractionation during trophic transfer, but the ability of fingerprints to resolve primary production sources is still unclear. Larsen et al. (2013) compared two dozen species of laboratory cultures comprising of diatoms, cyanobacteria, crysophytes, chlorophytes and haptophytes to macroalgae, seagrass, fungi, bacteria, and terrestrial vascular plants and found that of all these groups, phytoplankton displayed the largest intragroup variability in $\delta^{13} \mathrm{C}_{\mathrm{EAA}}$ patterns across species and types. Despite some unresolved questions for applying $\delta^{13} \mathrm{C}_{\mathrm{EAA}}$ fingerprints in marine environments, they have been applied successfully to track habitat use of fishes with distinct ontogenetic migration patterns (Vaneet al. 2018), resource and habitat use in marine systems (McMahon, Berumen \& Thorrold 2012), and proportional contributions of primary production sources to marine consumers (Vokhshoori, Larsen \& McCarthy 2014; Elliott Smith, Harrod \& Newsome 2018; Rowe et al.2019). A recent study on mesozooplankton in the Baltic Sea has shown promise in distinguishing between interannual algal assemblages (Egliteet al. 2019). Taken together, these results indicate that $\delta^{13} \mathrm{C}_{\mathrm{EAA}}$ fingerprints may be able to provide detailed insights into ecological niches of consumers to a much larger extend than previously realized.

Exploring further use of CSIA to elucidate changes in basal resources and ecological niches are particularly pertinent for regional seas because of their rapidly warming sea surface temperatures and increasing stressors from anthropogenic activities such as eutrophication and overfishing, with corresponding changes in food webs (Reusch et al. 2018). In this study, we selected the western and central Baltic Sea as a study area because it is a brackish inland sea characterized by strong differences in phytoplankton composition (Gasiūnaitè et al. 2005; Wasmund et al. 2017; Eglite et al. 2019) driven by a gradient in hydrographic-hydrochemical conditions (Naumann et al. 2017). In this sea, food web related processes have been identified as driver of changes in ecosystem composition (Möllmann et al.2009) and declines of key commercial species (Casini et al. 2016; Reusch et al. 2018). Compared to fully marine systems, this brackish system is characterized by a relatively low diversity (Ojaveeret al. 2010), and a tight coupling of benthic and pelagic food webs (Griffiths et al. 2017). Across the gradient, the small pelagic fish species herring and sprat are the dominant zooplanktivores, and of large commercial value (Ojaveer et al. 2018). As zooplanktivores, these species are also natural integrators of pelagic planktonic production.

To test the power of CSIA to identify niche differentiation among marine consumers in the spatially variable Baltic Sea, we obtained $\delta^{13} \mathrm{C}_{\mathrm{AA}}$ values for a range of species from different functional groups including suspension feeders, planktivores, benthic predators and scavengers. Furthermore, to assess the power of the method to identify differences across larger spatial scales, we obtained $\delta^{13} \mathrm{C}_{\mathrm{AA}}$ values for herring and sprat from four locations along the Baltic Sea gradient (Fig. 1). We first assessed the power of $\delta^{13} \mathrm{C}_{\mathrm{EAA}}$ fingerprints to identify (1) trophic niche differentiation among functional groups and among species, and (2) the presence of spatial patterns among planktivorous fishes, positing that different $\delta^{13} \mathrm{C}_{\text {EAA }}$ profiles of phytoplankton assemblages would propagate via mesozooplankton to zooplanktivore fishes. Finally, we assessed the potential of bulk $\delta^{13} \mathrm{C}$ and $\delta^{15} \mathrm{~N}$ data to provide complementary information about modes of feeding and trophic position.

\section{MATERIAL AND METHODS}

\subsection{Study system}

The Baltic Sea is a shallow (mean depth $58 \mathrm{~m}$ ) temperate regional sea, which displays a strong salinity gradient from marine salinity $\left(30 \mathrm{~g} \mathrm{~kg}^{-1}\right)$ at the connection to the North Sea in the west to near freshwater $\left(2 \mathrm{~g} \mathrm{~kg}^{-1}\right)$ in the north-eastern inner part (Meier et al. 2007). The Baltic environmental situation entails strong fluctuations in temperature and light availability, a horizontal salinity gradient and strong vertical stratification, low oxygen conditions in the deep parts of the basins (Carstensen et al. 2015), and an abundant nutrient supply due to eutrophication (Gustafsson et al. 2012), with seasonal minima when nutrients are taken up during phytoplankton blooms. Due to an accumulation of anthropogenic pressures on a level that is expected for other coastal seas, the system has been coined a "time machine for the future coastal oceans" 
(Reusch et al. 2018).

\subsection{Fauna sampling}

Sampling for this study took place during research cruise AL476 with research vessel ALKOR in April 2016 (see sampling stations in Fig. 1). All specimens were measured (total length or diameter to the nearest mm, mass to the nearest $\mathrm{g}$ ), ca. $0.5 \mathrm{~cm}^{3}$ of muscle tissue was taken for isotope analysis and immediately frozen at $-20 \mathrm{C}$ on board of the vessel for further analyses. Our sampling was designed with our two main research questions in mind: 1) can $\delta^{13} \mathrm{C}_{\mathrm{AA}}$ fingerprints differentiate feeding niches at functional group and species levels; and 2) is it possible to obtain geographically distinct fingerprints for widely distributed zooplanktivorous fishes. For the first research question, we collected the following species in the two westernmost sites, Kiel Bay and the Arkona Basin: planktivores (herring: Clupea harengusLinnaeus 1758) and (European sprat: Sprattus sprattus Linnaeus 1758), pelagic piscivore (Whiting: Merlangius merlangus Linnaeus 1758), suspension feeders (Ocean quahog: Arctica islandicaLinnaeus 1767, Blue mussels: Mytilus edulis Linnaeus 1758), benthic predatory flatfish (Common dab: Limanda limanda Linnaeus 1758, European flounder: Platichthys flesus Linnaeus 1758, European plaice: Pleuronectes platessa Linnaeus 1758), benthic predators (Common starfish: Asteria rubens Linnaeus 1758), and scavengers (Red whelk: Neptunea antiqua Linnaeus 1758). For the second research question, we also samples herring and sprat in the two easternmost sites, Bornholm Basin and Gdansk Basin. For further sample characteristics, see Table 1 for a summary and Supplementary S1 for detailed information.

\subsection{Phytoplankton assemblages}

Information of phytoplankton communities during the study period was obtained from publicly available plankton monitoring data published by Wasmund et al. (2017). The compiled phytoplankton data from January through May show that the phytoplankton spring bloom in 2016 occurred almost simultaneously in the Belt Sea, Arkona Basin and Bornholm Basin during the first half of March. The bloom was dominated by diatoms in Kiel Bay and increasingly by Mesodinium rubrum (a photosynthetic ciliate that relies on chloroplasts derived from its cryptophyte symbiont (Qiu, Huang \& Lin 2016)) along a western to eastern latitudinal gradient. We compiled the relative abundance of major algal groups based on the 10 most abundant phytoplankton taxa - see pie charts in Fig. 1. The most noticeable trends across the latitudinal gradient is the much greater diatom abundance in Kiel Bight than Gdansk Basin, and vice versa for the cryptophyte group. The total plankton production was smaller in the western than eastern sites; Kiel Bay: $488 \mu \mathrm{g} / \mathrm{L}$, Arkona Basin: $412 \mu \mathrm{g} / \mathrm{L}$, Bornholm Basin: $702 \mu \mathrm{g} / \mathrm{L}$, and Gdansk Basin: $796 \mu \mathrm{g} / \mathrm{L}$ (averages from three cruises January-May) (Wasmund et al. 2017).

\subsection{Stable isotope analysis}

Isotope data are expressed in delta $(\delta)$ notation: $\delta^{i} E_{\text {sample }}=\frac{\left(\frac{i_{E}}{j_{E}}\right)_{\text {sample }}-\left(\frac{i_{E}}{j_{E}}\right)_{\text {ref }}}{\left(\frac{i_{E}}{j_{E}}\right)_{\text {Ref }}}$ For the element E, the ratio of heavy (i) to light (j) isotope are measured in both sample and references (Coplen \& Shrestha 2016). To express the isotopic data as per mil (multiplied by 1000. The isotope ratios are expressed relative to international standards; Vienna Pee Dee Belemnite (VPDB) for carbon and atmospheric air for nitrogen.

All tissue samples for compound specific isotope analysis were freeze dried and then hydrolyzed in $6 \mathrm{~N} \mathrm{HCl}$ at $110^{\circ} \mathrm{C}$ for $20 \mathrm{~h}$ before derivatizing the AAs to $N$-acetyl methyl esters (NACME, (Corr, Berstan \& Evershed 2007) following the protocols by (Larsen et al. 2013; Larsen et al. 2016a). The samples were analysed at the Leibniz Laboratory at Kiel University. The average standard deviation for the samples, across all AAs was 0.3Elemental content and bulk isotope values were determined at the Stable Isotope Facility of the Experimental Ecology Group, GEOMAR, Kiel. The overall standard deviation for the measurement range 5.0-15.0 $\mu \mathrm{g} \mathrm{N}$ and 10.0-140 $\mu \mathrm{g} \mathrm{C}$ was \pm 0.2 lipid extraction prior to stable isotope analyses of tissue samples because this can affect $\delta{ }^{15} \mathrm{~N}$ values (Svenssonet al. 2016). Instead, we applied lipid correction to ${ }^{13} \mathrm{C}$ values with $\mathrm{C} / \mathrm{N}$ values larger than 3.3 (indicating elevated lipid content) following Post et al. (2007). For detailed CSIA and bulk SIA methods, see the Supplementary Information. AA See Supplementary Table S2 for $\delta^{13} \mathrm{C}$ values and Supplementary Table $\mathrm{S} 3$ for bulk $\delta^{13} \mathrm{C}$ and $\delta^{15} \mathrm{~N}$ values. 


\subsection{Statistical analyses}

All statistical analyses were performed in $\mathrm{R}$ version 3.5.1 (R-Development-Core-Team 2018). To assess whether EAA in consumers originate from bacteria, fungi or marine phytoplankton, we applied linear discriminant function analysis (LDA) (R: MASS ) using $\delta^{13} \mathrm{C}_{\mathrm{EAA}}$ training data from Larsenet al. (2013). To assess the power of differentiating among functional groups and among species with $\delta^{13} \mathrm{C}_{\mathrm{EAA}}$ data, we applied Principal Component Analysis (PCA, R: vegan ) using mean-centred $\delta^{13} \mathrm{C}_{\mathrm{EAA}}$ values to factor out baseline isotope variability. The mean-centred values were calculated by subtracting each individual $\delta^{13} \mathrm{C}_{\mathrm{EAA}}$ value from the mean $\delta^{13} \mathrm{C}$ values of all EAAs for each sample. Prior to the PCA, we applied LDA to find the most effective set of independent variables for predicting category membership. With this set of independent variables, we performed covariance matrix PCA that preserves variance as the range and scale of variables are in the same units of measure. Using the first and second principal component scores, we then applied Multivariate Analysis of Variance (MANOVA, R:manova) in conjunction with Pillai's trace to test the null hypothesis that groups have a common centroid in a dependent variable vector space. A rejection of this hypothesis entails that the groups have significantly different $\delta^{13} \mathrm{C}_{\text {EAA }}$ patterns or fingerprints. The MANOVA tests were performed on groups with [?] 5 specimens. To remove the effect of a covariate factor, we applied Multivariate Analysis of Covariance (MANOVA, R: jmv ). All data for multivariate comparisons were first assessed for homogeneity of variance by using Fligner-Killeen tests and visually checked for departures from normality on Q-Q plots. To test for species-specific $\delta^{13} \mathrm{C}$ differences for each EAA for consumers from Kiel Bight and the Arkona Basin, respectively, we used a One Way ANOVA with Tukey's HSD test (R: aov; TukeyHSD ). Using scatterplots, we also investigated the power of differentiating niches with isotope values of the glycolytic AAs and bulk carbon and nitrogen, respectively. We used linear modelling to test the strength of linear associations (R: $l m$ ).

\section{RESULTS}

\subsection{Biosynthetic origins of the essential amino acids}

According to our LDA using training data of broad phylogenetic groups, phytoplankton were the primary EAA source for all consumers in Kiel Bay and Arkona Basin; contributions from bacteria and fungi were small or possibly absent (Fig. 2). The discrete clustering of most functional groups indicates that they were supported by different phytoplankton sources, here listed in terms of association along the along the first linear discriminant: suspension feeders, benthic flatfish, scavengers, pelagic piscivores, planktivores and benthic predators.

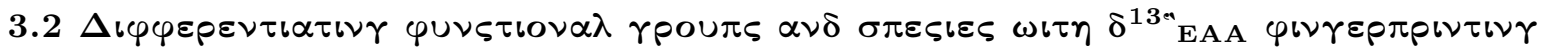

To further investigate the ability of $\delta^{13} \mathrm{C}_{\mathrm{EAA}}$ fingerprints to differentiate among functional groups and species, we used data from this study only. In terms of functional groups for the compiled Kiel Bay and Arkona Basin datasets, all six groups cluster separately (Fig. 3). Suspension feeders belong to the most distinct and isolated group; scavengers and benthic predators cluster adjacent to one another; pelagic piscivores, planktivores, and benthic flatfish also cluster adjacently. The median values of the five largest groups are significantly different (Pillai's Trace $=1.55, \mathrm{~F}_{6,112}=63.6 ; \mathrm{P}<0.001$ ). Our comparison between species for each site show that most sprat and herring specimens have similar principal component scores for Kiel Bay (Fig. 4A) and Arkona Basin (Fig. 4B). Sprat and herring cluster adjacent to the three species of benthic flatfish. Starfish and the two suspension feeding species each group in distinct and isolated clusters. We did not test for differences in median values at a species level because we had five or less specimens of each species. For both sites, the most effective set of variables for predicting species membership are Thr, Val and Met (Figs. 4A and 4B).

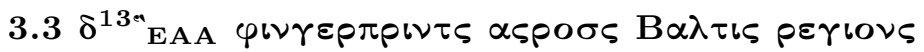

The $\delta^{13} \mathrm{C}_{\mathrm{EAA}}$ fingerprints of clupeids from the four Baltic Sea regions show region-specific clustering of most herring and sprat specimens (Fig. 5A and 5B). The separation was stronger for herring (Pillai's Trace = $1.05, \mathrm{~F}_{6,32}=5.9 ; \mathrm{P}<0.001$ ) than for sprat (Pillai's Trace $=0.90, \mathrm{~F}_{6,32}=4.4 ; \mathrm{P}<0.01$ ) due to larger 
principal component variability of the Arkona Basin specimens. The region-specific separation becomes weaker when joining the two clupeid species (see Fig. S1). To assess how ontogentic factors may have influenced the observed $\delta^{13} \mathrm{C}_{\mathrm{EAA}}$ fingerprints, we incorporated mass of individual specimens as a covariate using MANCOVA. The significance of these tests are practically similar to those obtained with MANOVA for both herring (Pillai's Trace $=1.06, \mathrm{~F}_{6,30}=5.6 ; \mathrm{P}<0.001$ ) and sprat (Pillai's Trace $=0.94, \mathrm{~F}_{6,30}=4.4$; $\mathrm{P}<0.01)$.

\subsection{Bulk stable isotopes}

Bulk $\delta^{13} \mathrm{C}$ and $\delta^{15} \mathrm{~N}$ values were not linearly correlated $(\mathrm{R}=0.004$; Fig. 6 , see bulk isotopic values in Table S2). Along the $\delta^{15} \mathrm{~N}$ axis, suspension feeders have more negative $\delta^{15} \mathrm{~N}$ values than the remaining functional groups (Fig. 6). Along the $\delta^{13} \mathrm{C}$ axis, planktivores have the most negative values, and scavengers and benthic predators the most positive $\delta^{13} \mathrm{C}$ values.

\section{DISCUSSION}

With accelerating global and regional environmental changes, identifying the properties and changes of food webs, including trophic niche partitioning among marine consumers, it is important to understand the resulting changes in biological systems. Here, we provide a systematic assessment of the potential of CSIA compared to traditional bulk $\mathrm{C}$ and $\mathrm{N}$ isotope analysis to elucidate resource partitioning and trophic niche differentiation of consumers in the Baltic Sea, a rapidly changing sea with a strong spatial environmental gradient.

\subsection{Understanding niche differentiation and resource partitioning with CSIA}

Our results show that the $\delta^{13} \mathrm{C}_{\mathrm{EAA}}$ fingerprinting method holds considerable potential for identifying feeding differences in marine habitats. In our two westernmost Baltic locations, the Kiel Bay and the Arkona Basin, we were able to identify niche differentiation among all putative functional groups, as well as most species. This differentiation is in agreement with previous knowledge based on traditional methods like stomach content analysis, e.g. Hislop et al. (1997). Species with similar modes of feeding clustered closely. It is surprising, however, that seastars clustered very differently than bivalves, considering that blue mussels are considered of major importance in their prey (Sommer, Meusel \& Stielau 1999). Such 'mismatches' do not pertain to limitations of the fingerprinting method, but rather to the extend a study has sampled and analysed all relevant endmembers. For example, seastars also feed on other invertebrates such as sponges, snails, and isopods (Anger et al. 1977). In addition, primary consumers integrate more recent photosynthates in their tissue than higher level consumers. Taken together, our results highlight the potential of $\delta^{13} \mathrm{C}_{\mathrm{EAA}}$ fingerprinting to elucidate the dietary niches of marine consumers, and how fluxes of carbon and nutrients from primary producers to detritus and consumers structure marine ecosystems (Cebrian 1999; Lartigue \& Cebrian 2012).

The highly dynamic and complex nature of marine food webs can make it challenging to assess trophic relationships between consumers and producers, particularly on a taxon specific level (Woodward et al. 2005; Armengol et al. 2019). The clear spatial and trophic group differences observed in our study underscore the potential of $\delta^{13} \mathrm{C}_{\mathrm{EAA}}$ fingerprinting to determine the trophic basis of production, i.e. how particular production sources are linked to consumers, and specifically selective grazing and assimilation of phytoplankton and detrital resources. Since phytoplankton assemblages influence the food web structure, it will be critical for future studies to establish a reference phytoplankton library based on well characterized in situ algal assemblages and single species cultures. As demonstrated in this study, laboratory cultures of bacteria, phytoplankton and other potential endmembers can be used as a proxy for in situ samples, which means that the fingerprinting approach works well for tracing inconspicuous sources. Increased application of this method to identify the taxonomic groups fuelling production on higher trophic levels could improve our understanding of trophic links in many marine food webs and reduce the current bias towards larger prominent species feeding on clearly identifiable food items.

\subsection{Assessing spatial differences in marine consumers and food webs with CSIA}


Spatial isotope differences of marine consumers can inform about underlying differences in the organic matter at the base of food webs, as well as migration patterns of individuals (Hansson et al.1997; McMahon, Berumen \& Thorrold 2012; Torniainen et al. 2017). The geographically distinct $\delta^{13} \mathrm{C}_{\mathrm{EAA}}$ fingerprints of herring and sprat observed in our study points to limited mixing among schools from the different locations, i.e., spatial population structuring, and to the presence of different isotopic baselines (e.g., different phytoplankton assemblages) among locations. This corresponds well with monitoring studies of phytoplankton in the Baltic Sea, highlighting the change in assemblages along the environmental gradient (Wasmund et al. 2017) (Fig. 2). The additional observation of substantial variability within the same locations for both sprat and herring could be related to size-related differences in feeding (Last 1989; Kleppel 1993; Casini, Cardinale \& Arrhenius 2004) as well as differences in migrations, both between areas (Aro 1988; Jørgensen et al. 2005; Gröhsler et al. 2013) and in the case of herring between coastal and offshore areas during spawning runs, e.g., (Šaškov et al. 2014). The lower spatial differentiation observed after pooling the two species is in line with a previous study in the Baltic; it found indiscernible fingerprints among regions after pooling multiple zooplankton species that differ in their dietary preferences and response to the trophic state (Pejler 1983; Gorokhova et al. 2016; Eglite et al. 2019). Our finding suggests that with further development, $\delta^{13} \mathrm{C}_{\mathrm{EAA}}$ fingerprinting have the potential to complement conventional tags and bulk isoscape approaches to track migrations in offshore system (St. John Glew et al.;Chittenden et al. 2013; Soto, Wassenaar \& Hobson 2013; Torniainen et al. 2017). It could also provide further and much needed insight into feeding ecology and response to changing physio-chemical conditions (Casini, Cardinale \& Arrhenius 2004; Kulke 2018).

\subsection{Towards a complementary toolset: combining new and old methods}

Isotope ecologists consider EAA to be among the most powerful carbon tracers because EAA carbon backbones are usually passed through multiple trophic levels with minimal modifications in contrast to bulk carbon. In that light, it is unsurprising that the power to differentiate among functional groups and species was higher for $\delta^{13} \mathrm{C}_{\mathrm{EAA}}$ than the bulk isotopes where it is possible to observe coarse trophic structuring and isotopic baseline differences. Given that the analytical costs for bulk $\mathrm{C}$ and $\mathrm{N}$ isotope analysis is about 20 times less than for CSIA, the question of applying bulk or CSIA in ecological studies is basically a choice between the need for high spatial and temporal resolution vs. high taxonomic resolution. We show that $\delta^{13} \mathrm{C}_{\mathrm{EAA}}$ provides an unprecedented insight into ecological niches and that it is more powerful than bulk $\mathrm{C}$ and $\mathrm{N}$ isotopes for tracking migration of fishes.

\subsection{Perspectives}

Our study highlights the applicability of $\delta^{13} \mathrm{C}_{\mathrm{EAA}}$ fingerprinting in a regional sea with strong salinity and temperature gradients by differentiating among the trophic niches of both functional groups and species at an unprecedented resolution, and by identifying spatial fingerprinting differences of widely distributed species. These differences are likely driven by regional differences in basal resources, i.e. algal composition, and the strength of trophic links between various phytoplankton producers and consumers. Our study also highlights how CSIA can provide new insights into food web structuring in spatially and temporally dynamic systems, and thus complement traditional tools in trophic ecology, including insights that are complementary to those from the "traditional" bulk stable isotope analysis.

Current marine food webs are predicted to be fragile and susceptible to structural changes with consequent alterations in the functioning of the ecosystem (Marina et al. 2018). As environmental changes are accelerating, it is crucial to understand whether and how quickly marine food webs can adapt to changes in phytoplankton assemblages and overexploitation of top predators. For this reason, it is key identifying and quantifying feeding interactions across trophic levels, from phytoplankton to zooplankton to higher trophic levels, but many of these interactions remain crucial knowledge gaps (Griffiths et al. 2017). The combination of $\delta^{13} \mathrm{C}_{\mathrm{EAA}}$ and the more affordable bulk stable isotope analysis holds considerable promise to address these gaps in the future.

\section{ACKNOWLEDGMENTS}

We thank Dr. Nils Andersen, Karsten Gramenz and Robert Priester for technical assistance at the Leibniz 
Laboratory for Isotope Research (University of Kiel), and the scientific and permanent crew of RV Alkor cruise AL476 for their support during fieldwork. The study was supported by the Cluster of Excellence 80 "The Future Ocean", which is a framework within the Excellence Initiative by the Deutsche Forschungsgemeinschaft (DFG). Sampling on board of RV Alkor took place in the framework of the BONUS BIO-C3 project. TL was supported by the Germany's Federal Ministry of Education and Research (BMBF) via LOMVIA (03V01459) and JD was in part supported by the BONUS XWEBS project, both supported by BONUS (Art 185), funded jointly by the EU and the German BMBF. We declare no conflict of interest.

\section{CONFLICT OF INTEREST}

None declared.

\section{AUTHOR CONTRIBUTION}

JD and TL conceived the study, JD collected the samples, TH determined bulk isotope values, TL conducted amino acid isotope analyses and performed statistical analysis, TL and JD wrote the manuscript, and all authors commented on it.

\section{DATA AVAILABILITY STATEMENT}

Data associated with this paper are available in the Supplementary Information.

\section{References}

Alheit, J., Möllmann, C., Dutz, J., Kornilovs, G., Loewe, P., Mohrholz, V. \& Wasmund, N. (2005) Synchronous ecological regime shifts in the central Baltic and the North Sea in the late 1980s. Ices Journal of Marine Science, 62, 1205-1215.

Anger, K., Rogal, U., Schriever, G. \& Valentin, C. (1977) In-situ investigations on the echinoderm Asterias rubens as a predator of soft-bottom communities in the western Baltic Sea. Helgoländer Wissenschaftliche Meeresuntersuchungen, 29, 439.

Armengol, L., Calbet, A., Franchy, G., Rodríguez-Santos, A. \& Hernández-León, S. (2019) Planktonic food web structure and trophic transfer efficiency along a productivity gradient in the tropical and subtropical Atlantic Ocean. Scientific Reports, 9, 2044.

Aro, E. (1988) Review of fish migration patterns in the Baltic Sea.

Bowser, A.K., Diamond, A.W. \& Addison, J.A. (2013) From Puffins to Plankton: A DNA-Based Analysis of a Seabird Food Chain in the Northern Gulf of Maine. Plos One, 8, e83152.

Casini, M., Cardinale, M. \& Arrhenius, F. (2004) Feeding preferences of herring (Clupea harengus ) and sprat (Sprattus sprattus) in the southern Baltic Sea. Ices Journal of Marine Science,61, 1267-1277.

Casini, M., Käll, F., Hansson, M., Plikshs, M., Baranova, T., Karlsson, O., Lundström, K., Neuenfeldt, S., Gårdmark, A. \& Hjelm, J. (2016) Hypoxic areas, density-dependence and food limitation drive the body condition of a heavily exploited marine fish predator. Royal Society open science, 3, 160416.

Cebrian, J. (1999) Patterns in the fate of production in plant communities. The American Naturalist, 154, 449-468.

Chittenden, C.M., Ådlandsvik, B., Pedersen, O.P., Righton, D. \& Rikardsen, A.H. (2013) Testing a model to track fish migrations in polar regions using pop-up satellite archival tags. Fisheries Oceanography, 22, $1-13$.

Coplen, T.B. \& Shrestha, Y. (2016) Isotope-abundance variations and atomic weights of selected elements: 2016 (IUPAC Technical Report).Pure and Applied Chemistry, 88, 1203-1224.

Corr, L.T., Berstan, R. \& Evershed, R.P. (2007) Development of $N$-acetyl methyl ester derivatives for the determination of $\delta^{13} \mathrm{C}$ values of amino acids using gas chromatography-combustion-isotope ratio mass 
spectrometry.Analytical Chemistry, 79, 9082-9090.

Eero, M., Hjelm, J., Behrens, J., Buchmann, K., Cardinale, M., Casini, M., Gasyukov, P., Holmgren, N., Horbowy, J. \& Hüssy, K. (2015) Eastern Baltic cod in distress: biological changes and challenges for stock assessment. Ices Journal of Marine Science, 72,2180-2186.

Eglite, E., Graeve, M., Dutz, J., Wodarg, D., Liskow, I., Schulz-Bull, D. \& Loick-Wilde, N. (2019) Metabolism and foraging strategies of mid-latitude mesozooplankton during cyanobacterial blooms as revealed by fatty acids, amino acids, and their stable carbon isotopes.Ecology and Evolution .

Elliott Smith, E.A., Harrod, C. \& Newsome, S.D. (2018) The importance of kelp to an intertidal ecosystem varies by trophic level: Insights from amino acid $\delta^{13} \mathrm{C}$ analysis. Ecosphere,9, e02516.

Fry, B. (2006) Stable isotope ecology . Springer, New York.

Gasiūnaitè, Z.R., Cardoso, A.C., Heiskanen, A.S., Henriksen, P., Kauppila, P., Olenina, I., Pilkaitytė, R., Purina, I., Razinkovas, A., Sagert, S., Schubert, H. \& Wasmund, N. (2005) Seasonality of coastal phytoplankton in the Baltic Sea: Influence of salinity and eutrophication. Estuarine, Coastal and Shelf Science,65, 239-252.

Gorokhova, E., Lehtiniemi, M., Postel, L., Rubene, G., Amid, C., Lesutiene, J., Uusitalo, L., Strake, S. \& Demereckiene, N. (2016) Indicator Properties of Baltic Zooplankton for Classification of Environmental Status within Marine Strategy Framework Directive.Plos One, 11, e0158326.

Griffiths, J.R., Kadin, M., Nascimento, F.J., Tamelander, T., Törnroos, A., Bonaglia, S., Bonsdorff, E., Brüchert, V., Gårdmark, A. \& Järnström, M. (2017) The importance of benthic-pelagic coupling for marine ecosystem functioning in a changing world. Global Change Biology, 23, 2179-2196.

Gröhsler, T., Oeberst, R., Schaber, M., Larson, N. \& Kornilovs, G. (2013) Discrimination of western Baltic spring-spawning and central Baltic herring (Clupea harengus L.) based on growth vs. natural tag information. Ices Journal of Marine Science, 70,1108-1117.

Hansson, S., Hobbie, J.E., Elmgren, R., Larsson, U., Fry, B. \& Johansson, S. (1997) The stable nitrogen isotope ratio as a marker of food-web interactions and fish migration. Ecology, 78,2249-2257.

Hislop, J., Bromley, P., Daan, N., Gislason, H., Heessen, H., Robb, A., Skagen, D., Sparholt, H. \& Temming, A. (1997) Database report of the stomach sampling project, 1991.

Hyslop, E. (1980) Stomach contents analysis - a review of methods and their application. Journal of Fish Biology, 17, 411-429.

Jorgensen, H.B., Hansen, M.M., Bekkevold, D., Ruzzante, D.E. \& Loeschcke, V. (2005) Marine landscapes and population genetic structure of herring (Clupea harengus L.) in the Baltic Sea.Molecular Ecology, 14, 3219-3234.

Kleppel, G. (1993) On the diets of calanoid copepods. Marine Ecology-Progress Series, 99, $183-183$.

Kulke, R. (2018) Investigations on the feeding behaviour of juvenile sprat (Sprattus sprattus L.) and herring (Clupea harengusL.).

Larsen, T., Pollierer, M.M., Holmstrup, M., D’Annibale, A., Maraldo, K., Andersen, N. \& Eriksen, J. (2016a) Substantial nutritional contribution of bacterial amino acids to earthworms and enchytraeids: A case study from organic grasslands. Soil Biology and Biochemistry,99, 21-27.

Larsen, T., Taylor, D.L., Leigh, M.B. \& O’Brien, D.M. (2009) Stable isotope fingerprinting: a novel method for identifying plant, fungal or bacterial origins of amino acids. Ecology, 90,3526-3535.

Larsen, T., Ventura, M., Andersen, N., O’Brien, D.M., Piatkowski, U. \& McCarthy, M.D. (2013) Tracing Carbon Sources through Aquatic and Terrestrial Food Webs Using Amino Acid Stable Isotope Fingerprinting.Plos One, 8, e73441. 
Larsen, T., Ventura, M., Maraldo, K., Triado-Margarit, X., Casamayor, E.O., Wang, Y.V., Andersen, N. \& O'Brien, D.M. (2016b) The dominant detritus-feeding invertebrate in Arctic peat soils derives its essential amino acids from gut symbionts. Journal of Animal Ecology .

Lartigue, J. \& Cebrian, J. (2012) Ecosystem productivity and carbon flows: patterns across ecosystems. The Princeton guide to ecology, III, 9, 320-329.

Last, J. (1989) The food of herring, Clupea harengus, in the North Sea, 1983-1986. Journal of Fish Biology, 34,489-501.

Marina, T.I., Saravia, L.A., Cordone, G., Salinas, V., Doyle, S.R. \& Momo, F.R. (2018) Architecture of marine food webs: To be or not be a 'small-world'. Plos One, 13, e0198217.

McClelland, J.W. \& Montoya, J.P. (2002) Trophic relationships and the nitrogen isotopic composition of amino acids in plankton.Ecology, 83, 2173-2180.

McMahon, K.W., Berumen, M.L. \& Thorrold, S.R. (2012) Linking habitat mosaics and connectivity in a coral reef seascape. 109,15372-15376.

McMahon, K.W., Fogel, M.L., Elsdon, T.S. \& Thorrold, S.R. (2010) Carbon isotope fractionation of amino acids in fish muscle reflects biosynthesis and isotopic routing from dietary protein. Journal of Animal Ecology, 79, $1132-1141$.

Mollmann, C., Diekmann, R., Muller-Karulis, B., Kornilovs, G., Plikshs, M. \& Axe, P. (2009) Reorganization of a large marine ecosystem due to atmospheric and anthropogenic pressure: a discontinuous regime shift in the Central Baltic Sea. Global Change Biology, 15,1377-1393.

Naumann, M., Umlauf, L., Mohrholz, V., Kuss, J., Siegel, H., Waniek, J. \& Schulz-Bull, D. (2017) Hydrographic-hydrochemical assessment of the Baltic Sea 2016. Marine Science Reports . Meereswiss. Ber., Warnemunde.

O'Brien, D.M., Fogel, M.L. \& Boggs, C.L. (2002) Renewable and nonrenewable resources: Amino acid turnover and allocation to reproduction in lepidoptera. Proceedings of the National Academy of Sciences of the United States of America, 99, 4413-4418.

Ojaveer, H., Jaanus, A., MacKenzie, B.R., Martin, G., Olenin, S., Radziejewska, T., Telesh, I., Zettler, M.L. \& Zaiko, A. (2010) Status of biodiversity in the Baltic Sea. Plos One, 5, e12467.

Ojaveer, H., Lankov, A., Raid, T., Pollumae, A. \& Klais, R. (2018) Selecting for three copepods - feeding of sprat and herring in the Baltic Sea. Ices Journal of Marine Science, 75,2439-2449.

Ojaveer, H., Olenin, S., Narščius, A., Florin, A.-B., Ezhova, E., Gollasch, S., Jensen, K.R., Lehtiniemi, M., Minchin, D. \& Normant-Saremba, M. (2017) Dynamics of biological invasions and pathways over time: a case study of a temperate coastal sea. Biological Invasions, 19, 799-813.

Pejler, B. (1983) Zooplanktic indicators of trophy and their food.Forest water ecosystems , pp. 111-114. Springer.

Post, D.M. (2002) Using stable isotopes to estimate trophic position: Models, methods, and assumptions. Ecology, 83, 703-718.

Post, D.M., Layman, C.A., Arrington, D.A., Takimoto, G., Quattrochi, J. \& Montaña, C.G. (2007) Getting to the fat of the matter: models, methods and assumptions for dealing with lipids in stable isotope analyses. Oecologia, 152, 179-189.

Qiu, D., Huang, L. \& Lin, S. (2016) Cryptophyte farming by symbiotic ciliate host detected in situ. Proceedings of the National Academy of Sciences, 113, 12208-12213.

R-Development-Core-Team (2018) R: A language and environment for statistical computing. R Foundation for Statistical Computing, Vienna, Austria. 
Reusch, T.B.H., Dierking, J., Andersson, H.C., Bonsdorff, E., Carstensen, J., Casini, M., Czajkowski, M., Hasler, B., Hinsby, K., Hyytiäinen, K., Johannesson, K., Jomaa, S., Jormalainen, V., Kuosa, H., Kurland, S., Laikre, L., MacKenzie, B.R., Margonski, P., Melzner, F., Oesterwind, D., Ojaveer, H., Refsgaard, J.C., Sandström, A., Schwarz, G., Tonderski, K., Winder, M. \& Zandersen, M. (2018) The Baltic Sea as a time machine for the future coastal ocean. Science Advances, 4 .

Rowe, A.G., Iken, K., Blanchard, A.L., O’Brien, D.M., Døving Osvik, R., Uradnikova, M. \& Wooller, M.J. (2019) Sources of primary production to Arctic bivalves identified using amino acid stable carbon isotope fingerprinting. Isotopes in Environmental and Health Studies , 1-19.

Šaškov, A., Šiaulys, A., Bučas, M. \& Daunys, D. (2014) Baltic herring (Clupea harengus membras) spawning grounds on the Lithuanian coast: current status and shaping factors**This study was supported by the Norwegian Financial Mechanism (project No. LT0047). Oceanologia,56, 789-804.

Scott, J.H., O'Brien, D.M., Emerson, D., Sun, H., McDonald, G.D., Salgado, A. \& Fogel, M.L. (2006) An examination of the carbon isotope effects associated with amino acid biosynthesis. Astrobiology,6, 867-880.

Sommer, U., Meusel, B. \& Stielau, C. (1999) An experimental analysis of the importance of body-size in the seastar-mussel predator-prey relationship. Acta Oecologica, 20, 81-86.

Soto, D.X., Wassenaar, L.I. \& Hobson, K.A. (2013) Stable hydrogen and oxygen isotopes in aquatic food webs are tracers of diet and provenance.Functional Ecology, 27, 535-543.

St. John Glew, K., Graham, L.J., McGill, R.A.R. \& Trueman, C.N. Spatial models of carbon, nitrogen and sulphur stable isotope distributions (isoscapes) across a shelf sea: An INLA approach. Methods in Ecology and Evolution, 0 .

Svensson, E., Schouten, S., Hopmans, E.C., Middelburg, J.J. \& Damste, J.S.S. (2016) Factors controlling the stable nitrogen isotopic composition $\left(\delta^{15} \mathrm{~N}\right)$ of lipids in marine animals.PLoS ONE, 11 .

Torniainen, J., Lensu, A., Vuorinen, P.J., Sonninen, E., Keinänen, M., Jones, R.I., Patterson, W.P. \& Kiljunen, M. (2017) Oxygen and carbon isoscapes for the Baltic Sea: Testing their applicability in fish migration studies. Ecology and Evolution, 7, 2255-2267.

Vane, K., Larsen, T., Scholz-Böttcher, B.M., Kopke, B. \& Ekau, W. (2018) Ontogenetic resource utilization and migration reconstruction with $\delta^{13} \mathrm{C}$ values of essential amino acids in the Cynoscion acoupa otolith. Ecology and Evolution, 8, 9859-9869.

Vokhshoori, N., Larsen, T. \& McCarthy, M. (2014) Reconstructing $\delta^{13} \mathrm{C}$ isoscapes of phytoplankton production in a coastal upwelling system with amino acid isotope values of littoral mussels. Marine Ecology Progress Series, 504, 59-72.

Wasmund, N., Dutz, J., Pollehne, F., Siegel, H. \& Zettler, M.L. (2017) Biological assessment of the Baltic Sea 2016. Marine Science Reports . Meereswiss. Ber., Warnemünde.

Whiteman, J.P., Elliott Smith, E.A., Besser, A.C. \& Newsome, S.D. (2019) A Guide to Using CompoundSpecific Stable Isotope Analysis to Study the Fates of Molecules in Organisms and Ecosystems.Diversity, 11,8 .

Woodward, G., Speirs, D.C., Hildrew, A.G. \& Hal, C. (2005) Quantification and resolution of a complex, size-structured food web.Advances in Ecological Research, 36, 85-135.

Table 1. Sampling summary for research cruise AL476 with research vessel ALKOR in April 2016. CSIA indicates the number of specimens analysed for compound specific stable isotope analysis and BSIA the number of specimens analysed for bulk stable isotope analysis. 


\begin{tabular}{|c|c|c|c|c|c|c|}
\hline Basin & Species & Func. group & CSIA (n) & BSIA (n) & Length mean [min-max] $(\mathrm{cm})$ & Mas: \\
\hline$\overline{B a s i n}$ & Species & Func. group & CSIA (n) & BSIA (n) & Length mean [min-max] $(\mathrm{cm})$ & Mas: \\
\hline \multirow[t]{7}{*}{ Kiel Bight } & Arctica islandica & suspension & 5 & 5 & $3.6[3.2-4.0]$ & 12 \\
\hline & Asterias rubens & benthic predator & 5 & 5 & $8.5[5.5-12.2]$ & \\
\hline & Clupea harengus & planktivore & 5 & 5 & $14.4[12.5-16.5]$ & 22 \\
\hline & Limanda limanda & benthic flatfish & 5 & 5 & $18.2[14.5-21.5]$ & \\
\hline & Neptunea antiqua & scavenger & 3 & 3 & $5.1[4.3-5.8]$ & \\
\hline & Platichthys flesus & benthic flatfish & 5 & 5 & $27.8[25.5-30.0]$ & 22 \\
\hline & Sprattus sprattus & planktivore & 5 & 5 & $9.6[7.0-11.5]$ & 7.5 \\
\hline \multirow[t]{7}{*}{ Arkona Basin } & Asterias rubens & benthic predator & 5 & 5 & $6.2[5.2-7.6]$ & 8.3 \\
\hline & Clupea harengus & planktivore & 5 & 5 & $20.0[12.0-25.0]$ & 63 \\
\hline & Merlangius merlangus & pelagic piscivore & 5 & 0 & $31.4[29.0-35.0]$ & 26 \\
\hline & Mytilus edulis & suspension & 5 & 5 & $4.2[2.4-5.4]$ & 5.1 \\
\hline & Platichthys flesus & benthic flatfish & 5 & 5 & $26.4[19.0-37.0]$ & 19 \\
\hline & Pleuronectes platessa & benthic flatfish & 5 & 5 & $31.4[27.5-45.0]$ & 38 \\
\hline & Sprattus sprattus & planktivore & 5 & 5 & $12.5[11.5-13.0]$ & 14 \\
\hline \multirow[t]{2}{*}{ Bornholm Basin } & Clupea harengus & planktivore & 5 & 5 & $16.6[15.5-17.0]$ & \\
\hline & Sprattus sprattus & planktivore & 5 & 5 & $11.7[11.0-12.5]$ & \\
\hline \multirow[t]{2}{*}{ Gdansk Basin } & Clupea harengus & planktivore & 5 & 5 & $20.0[17.0-22.5]$ & \\
\hline & Sprattus sprattus & planktivore & 5 & 2 & $10.4[9.5-11.0]$ & 7. \\
\hline
\end{tabular}

Figure captions

Figure 1. Sampling stations in the Baltic Sea for the AL476 cruise (fauna; filled red circles) and black filled squares for the IOW stations (phytoplankton monitoring (Wasmund et al. 2017). The color gradient on the map shows showing surface concentration of the chlorophyll-a in April 152016 observed by satelite and supplemented by the results of the ecohydrodynamic model EcoSat (http://satbaltyk.iopan.gda.pl). The four pie charts present the relative biomass fraction of major taxonomic algal groups integrating three cruises from January to May 2016 (Wasmund et al. 2017). 'Het.' is an abbreviation for heterotrophic.

Figure 2. Linear discriminant function analysis based on $\delta^{13} \mathrm{C}_{\mathrm{EAA}}$ values of training data comprising of bacteria, fungi and marine phytoplankton (Larsen et al. 2013) and consumers from this study. The phytoplankton comprise of eight diatom samples (D1-D5; N1-N3), four chrysophytes (X1-X4), four haptophytes (H1 - H4), two chlorophytes (K1 \& K2) and one cryptophyte (Y1) - see Larsen et al. (2013) for sample codes. The ellipses represent $95 \%$ confidence intervals of each endmember, and the arrows represent the relative weightings of the independent variables for creating the discriminant function.

Figure 3. Principal component analysis for functional groups using mean-centred $\delta^{13} \mathrm{C}_{\mathrm{EAA}}$ values of consumers from Kiel Bay and Arkona Basin. Values in parentheses are the percentage variations accounted by each axis. The two axes account for $82 \%$ of the variations. The ellipses signify $95 \%$ confidence boundaries for each group.

Figure 4. Principal component analysis for species using $\delta^{13} \mathrm{C}_{\mathrm{EAA}}$ values centred to the EAA mean of consumers from Kiel Bay (A) and Arkona Basin (B), respectively. Values in parentheses are the percentage variations accounted by each axis. In $\mathrm{A}$ and $\mathrm{B}$, the first two axes account for $84 \%$ and $83 \%$ of the variations, respectively. The ellipses signify $95 \%$ confidence boundaries for each group.

Figure 5. Principal component analysis with $\delta^{13} \mathrm{C}_{\mathrm{EAA}}$ values centred to the EAA mean of herring (A) and sprat (B), respectively. The convex hulls represent the maximum range in PC1 and PC2 scores for each of the four sampling locations. The most important EAA for variations among locations are displayed in two 
first ordination components. Values in parentheses are the percentage variations accounted by each axis. In $\mathrm{A}$ and $\mathrm{B}$, the first two axes account for $95 \%$ and $92 \%$ of the variations, respectively.

Figure 6. Bulk $\delta^{13} \mathrm{C}$ and $\delta^{15} \mathrm{~N}$ values of Kiel Bay and Arkona Basin consumers of major functional groups. The scatterplots show bulk $\delta^{13} \mathrm{C}$ and $\delta^{15} \mathrm{~N}$ are uncorrelated; however, trophic structuring is apparent from the marginal density plots. Bulk isotope values of pelagic predators are missing (Table S3).

Figures

Figure 1

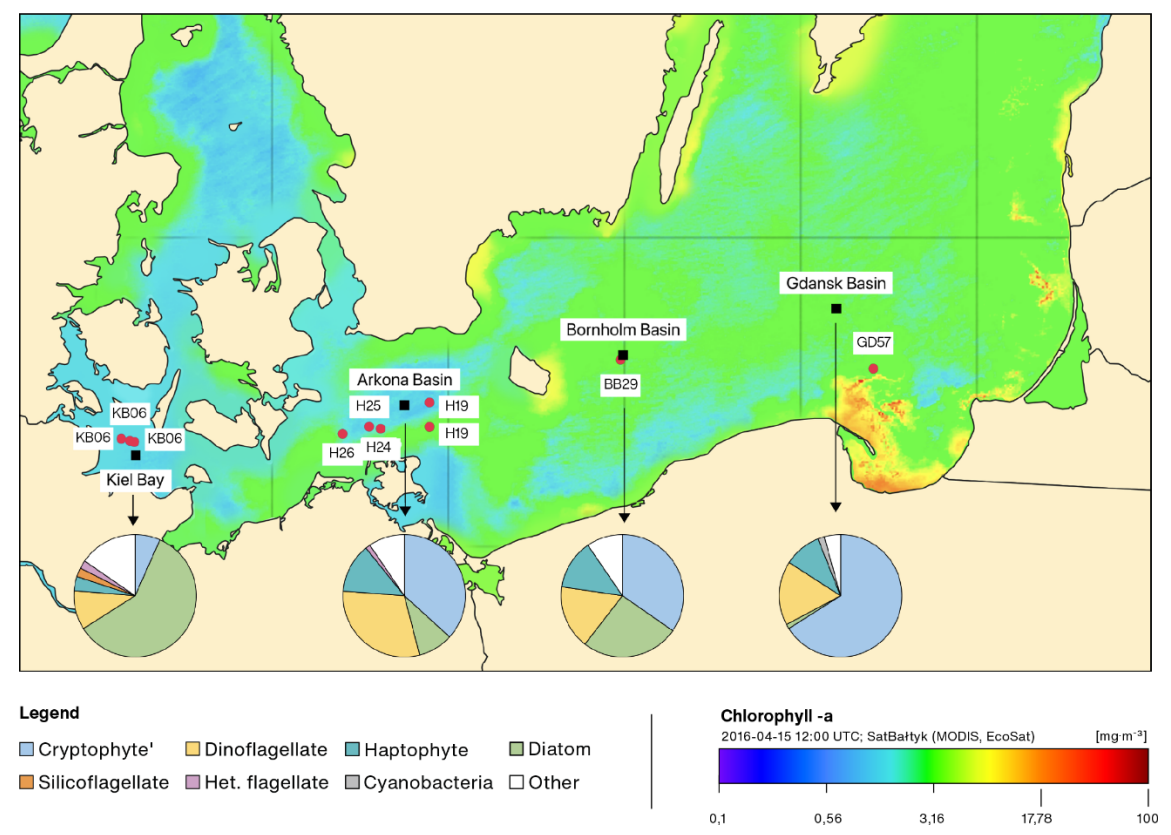

Figure 2

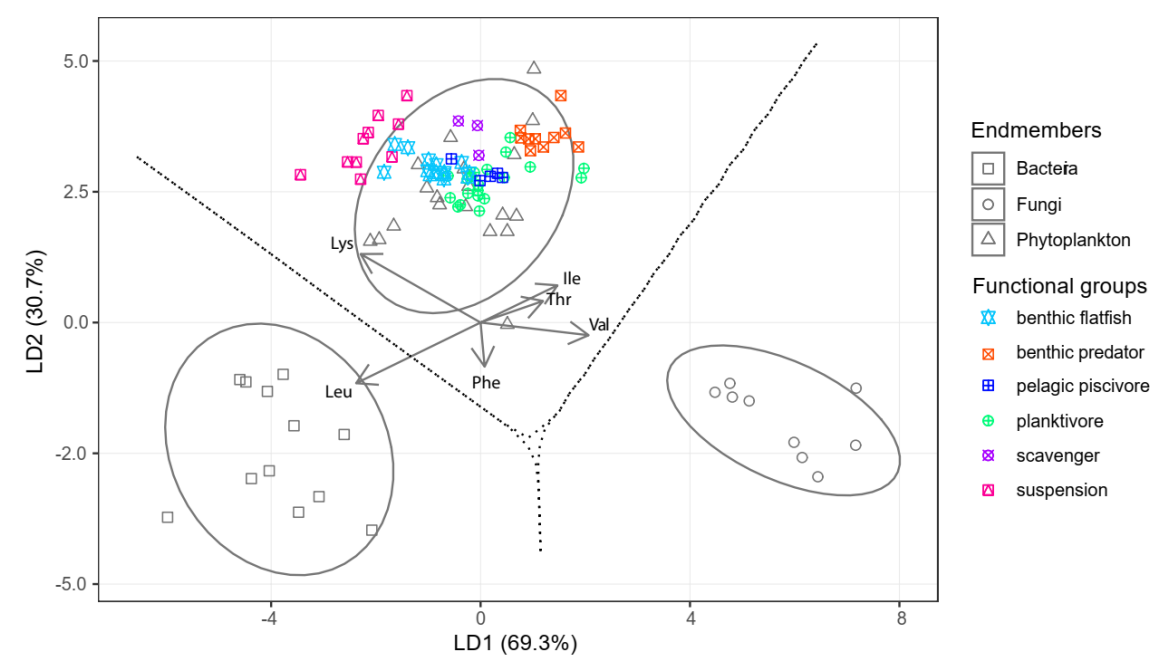

Figure 3 


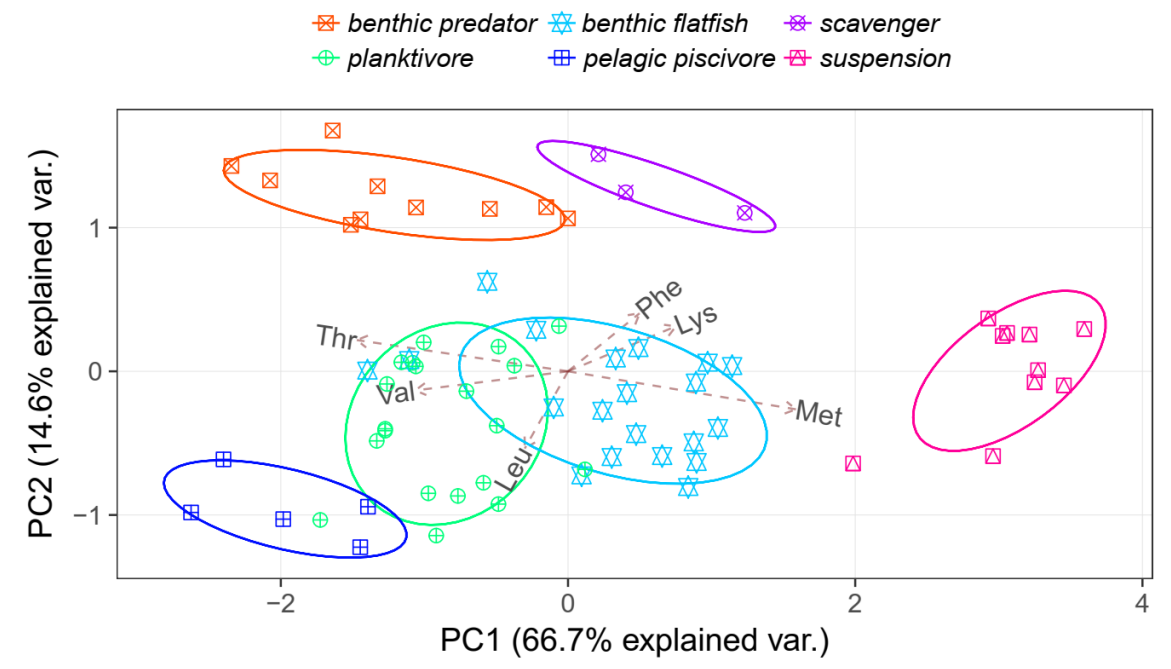

Figure 4 


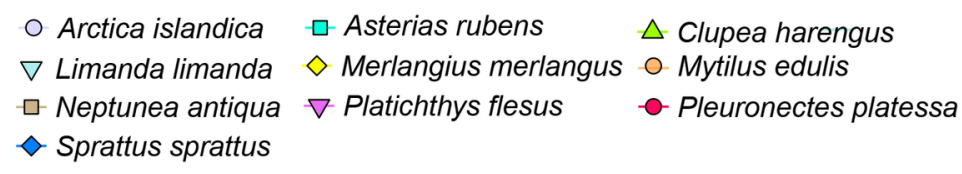

A
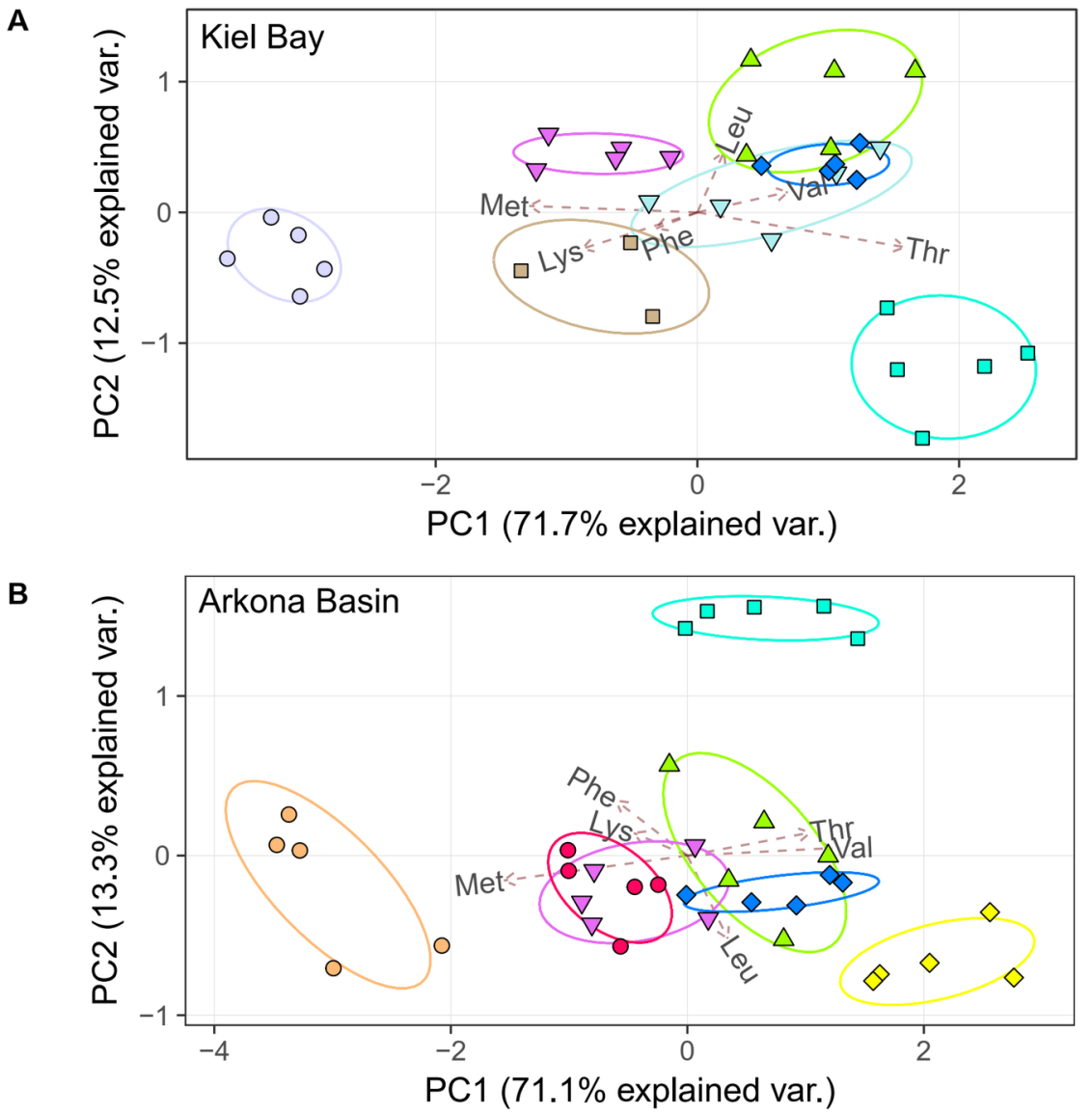

Figure 5 

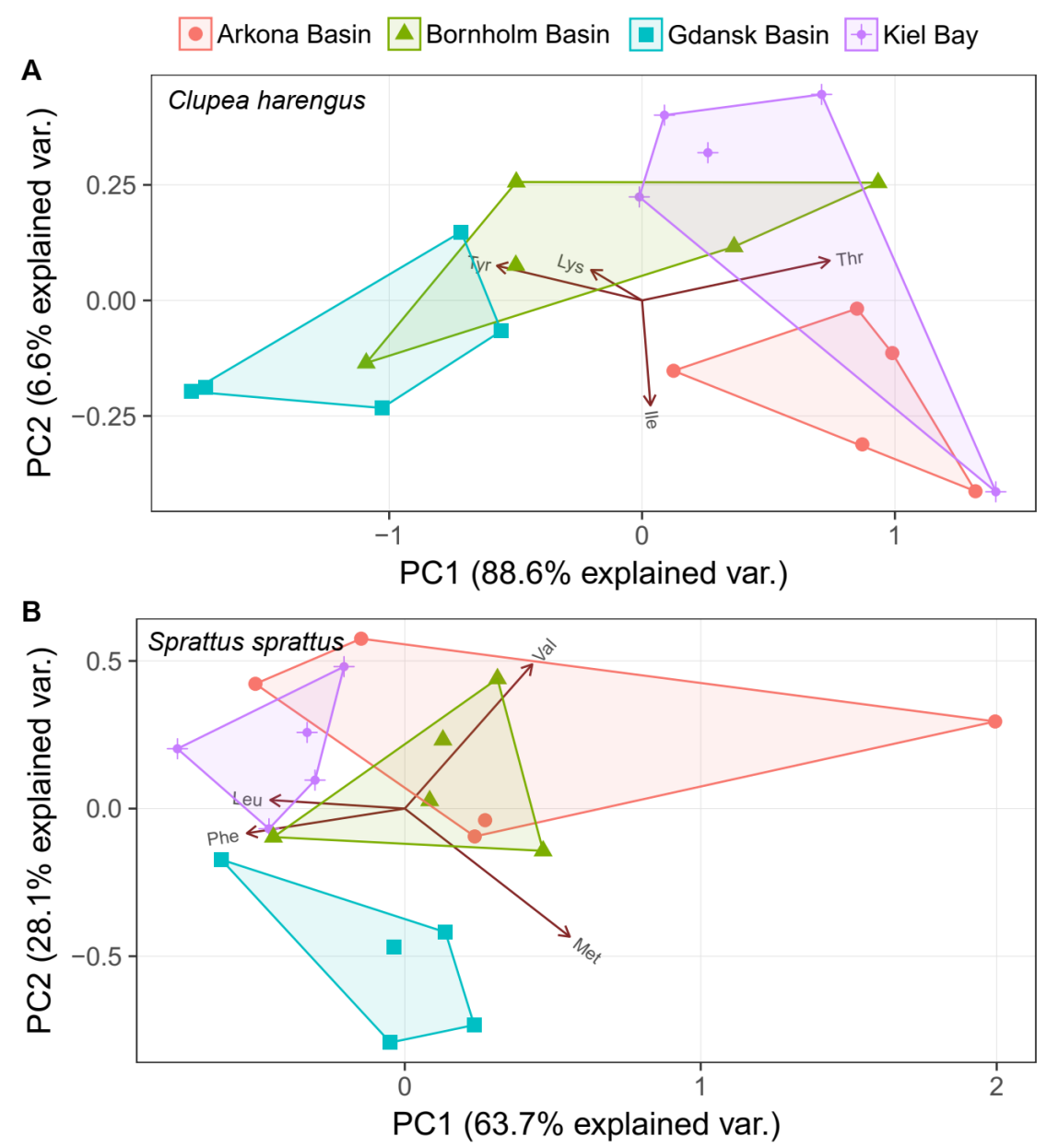

Figure 6

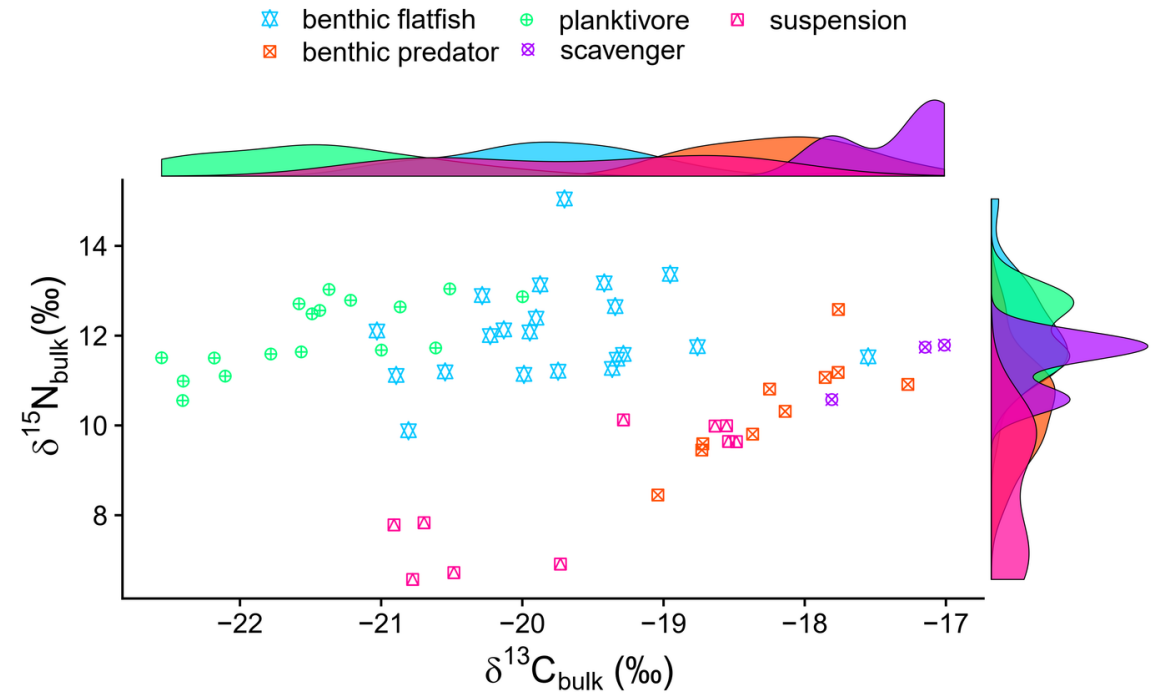




\section{Textbox}

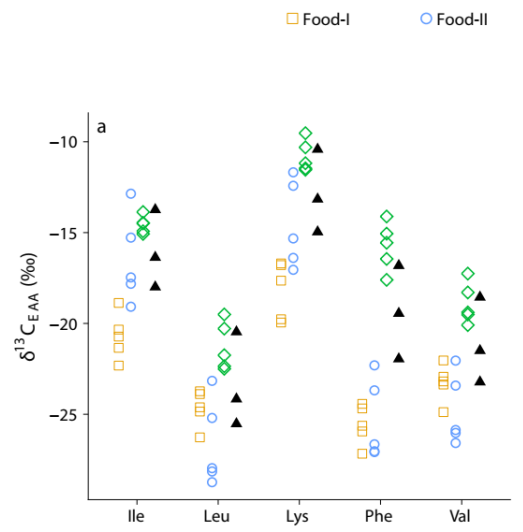

$\diamond$ Food-III $\quad \Delta$ Consumer
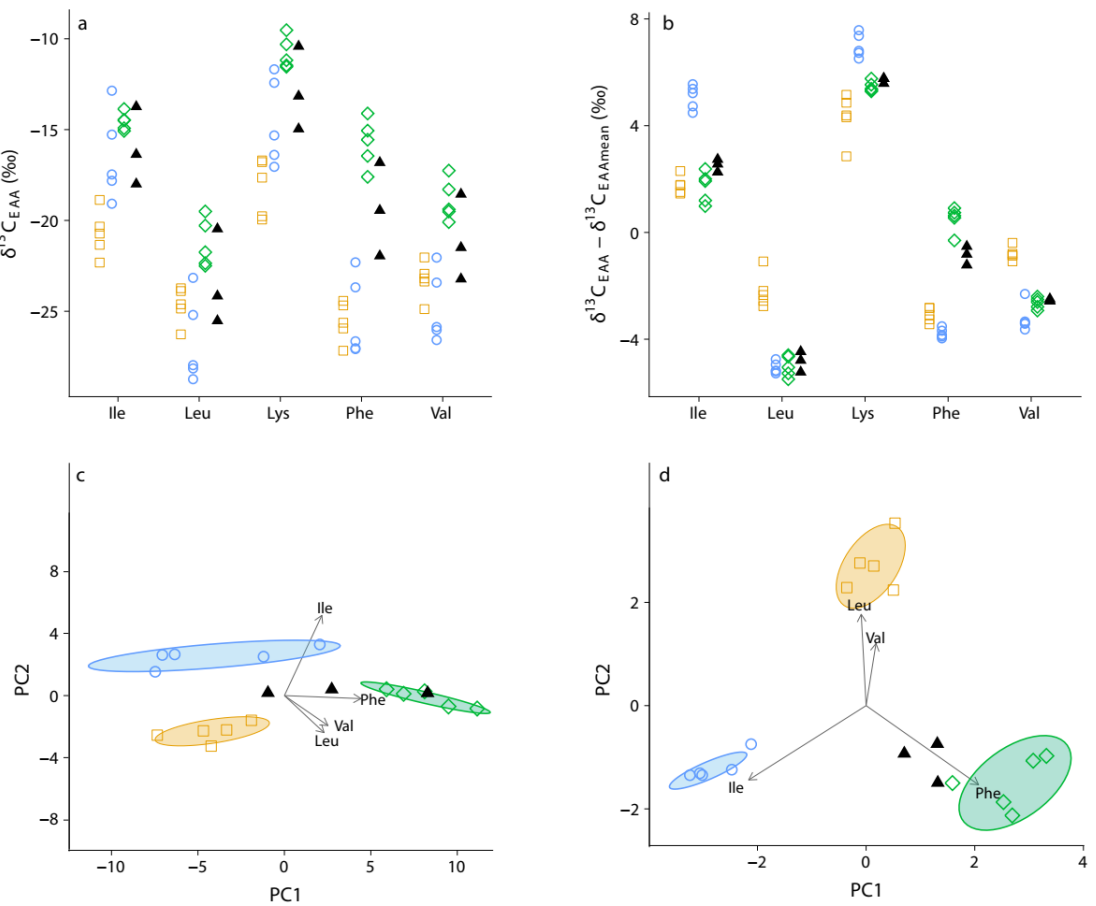

Carbon isotope fingerprinting of essential amino acids (EAA). This conceptional model depicts $\delta^{13} \mathrm{C}_{\mathrm{EAA}}$ values of consumers feeding in both estuarine and marine habitats. The consumers and their potential food sources mirror $\delta^{13} \mathrm{C}$ baseline values along this salinity gradient, and the $\delta{ }^{3} \mathrm{C}_{\mathrm{EAA}}$ intramolecular variability are from Larsen et al. (2015). The two plots in the left pane (a and c ) are based on baseline $\delta^{13} \mathrm{C}_{\mathrm{EAA}}$ values, and the two plots in the right pane ( $\mathbf{b}$ and $\mathbf{d}$ ) are based on $\delta^{13} \mathrm{C}_{\mathrm{EAA}}$ values centred to the $\delta^{13} \mathrm{C}$ mean across all EAA of a given sample.a , varying biogeochemical conditions across the estuarinemarine gradient cause highly variable $\delta^{13} \mathrm{C}_{\mathrm{EAA}}$ values. $\mathbf{b}$, this variability is greatly reduced within each food source when centring the $\delta^{13} \mathrm{C}_{\mathrm{EAA}}$ values of each sample to the mean of all five EAA. $\mathbf{c}$, to find out which combination of variables explain most of the variability among the three food sources, we applied Principal Component Analysis (PCA), an unsupervised dimensionality reduction method. Prior to the PCA we omitted lysine because it is the least informative EAA for separating the three food groups. Since the PCA is based on baseline $\delta^{13} \mathrm{C}$ values, the PCA factor scores (PC1 and PC2 coordinates) are influenced by both baseline and intermolecular $\delta^{13} \mathrm{C}$ variability.d , by using mean-centred data in the PCA, we have generated a $\delta^{13} \mathrm{C}_{\mathrm{EAA}}$ fingerprint where the resulting factor score variability within each group is reduced substantially. By factoring out $\delta^{13} \mathrm{C}$ baseline variability and instead using the source diagnostic power of $\delta^{13} \mathrm{C}_{\mathrm{EAA}}$ fingerprinting, it is now evident that regardless of habitat use all three consumers derive most of their dietary EAA from Food-III. Abbreviations used on the $\mathrm{x}$-axes ina and $\mathbf{b}$ : Ile $=$ isoleucine, Leu $=$ leucine, Lys $=$ lysine, Phe $=$ phenylalanine, $\mathrm{Val}=$ valine 